\title{
PREVALENCE OF SMOKING BEHAVIOR AMONG 10-19 YEARS CHILDREN IN PESHAWAR
}

\section{RUBEENA GUL ${ }^{1}$, HAYAT MUHAMMAD KHAN ${ }^{1}$, ZIA UR REHMAN ${ }^{1}$, SARDAR RAHEEL ALAM $^{1}$, NAEEMULLAH ${ }^{2}$}

1. Department of Community Medicine, Khyber Medical College Peshawar.

2. Department of Community Medicine, Saidu Medical College Swat.

\begin{abstract}
BACKGROUND: Smoking is a major public health problem and is one of the major preventable causes of premature deaths and diseases in the world. Fourteen to sixteen year olds are among a vulnerable group of individuals in society and susceptible to cigarette smoking. The objective was to find out the prevalence of cigarette smoking in the 10-19 year old students.

Methodology: A cross-sectional study was conducted in four randomly selected public and private schools of Peshawar in 2014. 500 students between 10 to 19 years participated in the study through simple random sampling technique. Data was analyzed on Excel.

Result: Of the total $130(26 \%)$ smoked and majority belonged to low socioeconomic status. $70(53.84 \%)$ started smoking at the age of 14-16 years. The study revealed that adolescents are adequately aware of the harms of smoking. Overall the level of awareness was found unsatisfactory. Parents can set a positive example for their children by not smoking themselves, and keeping their homes smoke-free also schools can provide tobacco prevention programs to educate students about the dangers of smoking.

Keywords: Smoking, Prevalence, Socioeconomic, Awareness, Initiation.
\end{abstract}

\section{INTRODUCTION}

WHO identifies adolescence as the period in human growth and development that occurs after childhood and before adulthood, from ages 10$19^{1}$.Young people are commonly regarded as healthy and for that reason few attempts have been made to systematically measure their health. Yet adolescence and young adulthood coincide with major changes in health problems and determinants of health in later $\operatorname{life}^{2}$. It represents one of the critical transitions in the life span. Ten to nineteen year olds are among a vulnerable group of individuals in society and susceptible to cigarette smoking. Unfortunately, persons who begin to smoke at a younger ages are more likely to experience the adverse health consequences from smoking ${ }^{3}$, these risk processes may lead to chronic noncommunicable diseases in later life, which emerge around this time ${ }^{4}$. Also smoking leads to premature death and is a huge economic burden on health systems and families of smokers, especially in developing countries like Pakistan with already limited resources. Smoking is one of the leading causes of preventable morbidity and mortality ${ }^{5}$. As there are nearly 1 billion smokers in the world, smoking kills 6 million people every year world wide. Two thirds of these smokers live in low- and middle-income countries $^{6}$. The rising burden of smoking in these countries is attributed to aggressive marketing strategies of large multinational tobacco companies $^{7}$. According to an estimate, 59 countries of the world conduct tobacco surveys regularly once every five years targeting only the adult population ${ }^{8}$.

Pakistan is the sixth most populous country of the world with a population of nearly 190 million 9 . The population age 15-24 in Pakistan was estimated to be approximately 27 million in 2000, and it is expected to increase, reaching 44.6 million in $2020^{10}$. Pakistan is among the 
few countries in the world where use of tobacco is alarmingly increasing ${ }^{11}$ as tobacco users in Pakistan amounts to 25 million ${ }^{12}$.Use of tobacco is very common in this part of the world as majority of adolescences use tobacco in any of the available form ${ }^{13}$. But cigarette is the most popular form of tobacco in use ${ }^{14}$. Recent surveys in many of the cities of Pakistan reveal that the ratio of smoking among youth is at rise; unfortunately most of the effected adolescents are below eighteen years of age ${ }^{15}$.

Objectives of the study was to measure the prevalence of cigarette smoking use among10-19 years youth and the socio economic determinants to the harmful effects of cigarette smoking in public and private schools of Peshawar in 2014.

\section{MATERIAL AND METHODS}

A cross-sectional survey was conducted from April to May 2014. A sample of 500 students between ages of 10-19 years studying in randomly selected four private and public schools of Peshawar.

The sample of the study was selected by simple random sampling technique. 125 male students were selected from each institute and 31 students from each class.

The variables under study were determinants of smoking, such as age, education, socioeconomic status, and age of initiation i.e. At what age they started smoking, positive family influence i.e. parent or a sibling a smoker, peer influence and awareness of the injurious effects of smoking on the health were included in the questionnaire. Current smokers were defined as having smoked in the last month. Ex-smokers were those who had stop smoking for last one month. A structured questionnaire was used for collection of data. All of the data from questionnaires was double-entered into SPSS and MS Excel software and checks were made to identify discrepancies. The data was presented in form of tables.

\section{RESULTS}

Out of 500 respondents 130 (26\%) of population smoked off which $77(59.2 \%)$ were current smoker and $53(40.7 \%)$ were ex- smoker see table 1. 38(29.3\%) off current smoker were from government school and $39(30 \%)$ were from private school while $22(16.9 \%)$ and $31(23.8 \%)$ of ex-smokers were from government and private schools respectively. Current smoking was most prevalent in age group of 14-16 years $40(51.91 \%)$. Overall 70(53.84\%) started smoking at the age of $14-16$ years $38(29.2 \%)$ at the age of 17-19 years while rest started at 13 years of age.

Table 01: Prevalence of smoking among 10-19 years children in Peshawar

\begin{tabular}{|c|c|}
\hline Status & $\mathbf{N = 5 0 0}$ \\
\hline Smoking & $130(26 \%)$ \\
\hline Non smoking & $370(74 \%)$ \\
\hline
\end{tabular}

Percentage of the current smokers were more $55(71.4 \%)$ in families with income of Rs 10000 or less per month while $38(71.6 \%)$ of ex smoker belonged to Rs 10000 and above per month income see table 2 .

Table 02: Relationship between smoking and monthly income among 10-19 years children in Peshawar

\begin{tabular}{|c|c|}
\hline Monthly income (rs) & Smoker N=130 \\
\hline$<10000$ & $70(53.85 \%)$ \\
\hline $10000-25000$ & $22(16.92 \%)$ \\
\hline$>25000$ & $38(29.23 \%)$ \\
\hline Total & $130(100 \%)$ \\
\hline
\end{tabular}

Students who had positive family influence of tobacco use had higher risk of current smoking. A Positive family influence was observed in $77(59.2 \%)$ of the study population off which $14(10.8 \%), 19(14.6 \%)$ and $44(33.8 \%)$ had a father, brother and cousins respectively who were smokers. While out of remaining $53(40.8 \%)$, half of them smoked only in college under peer pressure while rest smoke by getting impresses by media campaigns. $56 \%$ of the current smokers expressed their desire to quit 
smoking while $67 \%$ of them were willing to participate in the anti smoking activities.

There was substantial agreement among both smokers as well as non-smokers that smoking is harmful for health. 268(72.4\%) of non smoker responded that it causes lung cancer while $99.2 \%$ of the smokers agreed that it causes respiratory disease like asthma and breathing problem. Only $270(72.9 \%)$ of the non smokers agreed that smoking was related to teeth and gum diseases as compared to smokers $82(63.07 \%)$.

\section{DISCUSSION}

The prevalence of smoking among school students was found higher as compared to earlier studies conducted in Peshawar and other institutes ${ }^{16}$. Specifically, the smoking status of parents, siblings and peers is related to the smoking status of adolescence. Moreover, the greater the number of parents, siblings and peers who smoke, the more likely it is that a youth will be a smoker. This suggests that efforts to increase the number of smoke free homes and school may be warranted. Studies have shown that smoking restrictions at home not only reduce the overall exposure of tobacco, it can also reduce the smoking uptake in youth ${ }^{17}$. If individuals are not allowed to smoke inside the home, it sends a clear message to youth that smoking is a socially un-acceptable and nonnormative behavior. As parental smoking behaviors have been found to play a key role not only in youth initiation but also in the escalation of their smoking habits ${ }^{18}$. Studies indicate that youth having at least one smoking parent are more likely to begin smoking themselves ${ }^{19}$. Others have suggested that children with at least one smoking parent are significantly more likely to progress to higher levels of smoking, compared to children whose parents do not smoke. It has been observed that a young person's decision to smoke is directly influenced by peers' smoking behavior In terms of smoking initiation, smokers whose friends smoke are significantly more likely to begin smoking compared to never smokers whose friends do not smoke, even after adjusting for other variables ${ }^{2}$.

Both the smokers and nonsmokers were well aware of the adverse health effects of smoking indicating that mere provision of information on hazards of smoking may not be enough to reduce the prevalence of smoking. There is positive evidence that most students both smokers and non smokers admit knowing that smoking is harmful to their health but they still smoke. At any rate, it appears important that both public and private schools should be made to understand how and to what extent smoking adversely affects the health of the youth.

Our study revealed that smoking was more prevalent in low socioeconomic group as they may face higher exposure to tobacco's harms. Uptake may also be higher among those with low socioeconomic status, and quit attempts are less likely to be successful. Studies have suggested that this may be the result of reduced social support for quitting, low motivation to quit, stronger addiction to tobacco or increased likelihood of not completing to behavioral support sessions ${ }^{21}$. As evidence of interventions that work among lower socioeconomic groups is sparse.

The age of onset of smoking is becoming younger and younger ${ }^{22}$, which is consistent with our study. This is likely to increase the risk of development of avoidable tobacco-related illnesses at an earlier age. This means that young smokers who develop chronic tobacco-related illnesses require medical care for many years, increasing the cost of treating tobacco-related disease. Within the next few years, effective prevention programs against smoking must be developed, particularly for the lower socioeconomic populations, to prevent the cost of health care systems spiraling during the next few decades.

\section{CONCLUSION}

Despite the shortcomings, our study suggests that the factors which influence students to 
smoke are not significantly different from counties with a broader evidence base. As such, it helps justify the need for the government to adopt smoke free places, public education and treatment for tobacco cessation. Our results are consistent with other studies of adult smoking in Pakistan. The high prevalence among students is particularly concerning given that rates are typically higher among low socioeconomic populations. Finally, the study lays an important foundation for future research. It helps to justify the need for larger, more sophisticated trials on tobacco use among young adults in Pakistan.

\section{REFERENCES}

1. http://www.who.int/maternal_child_adole scent/topics/adolescence/dev/en/

2. Kleinert S. Adolescent health: an opportunity not to be missed. Lancet 2007; 369: 1057-58.

3. Reducing the Health Consequences of Smoking: 25 Years of Progress: A Report of the Surgeon General. Rockville, Md: US Dept of Health and Human Services; 1989:259-644. DHHS publication CDC 898411.

4. Gore F, Bloem P, Patton GC, et al. Global burden of disease in young people aged 10-24 years: a systematic analysis. Lancet 2011; 377: 2093-102.

5. World Health Organization: WHO report on the global tobacco epidemic, 2011: warning about the dangers of tobacco.

6. World Health Organization, Media Centre: Tobacco, Fact Sheet N 339. http://www.who.int/mediacentre/factsheets/fs339/en/i ndex.html website

7. Action on smoking and Health (ASH): ASH Fact Sheet on: Tobacco and the developing world. http://www.ash.org.uk website

8. World Health Organization, Media Centre: Tobacco, Fact Sheet N 339. http://www.who.int/mediacentre/factsheets/fs339/en/i ndex.html website

9. Central Intelligence Agency: The World Fact book, Pakistan.

10. Khan A. Adolescents and reproductive health in Pakistan: a literature review, 2000. Report No.11. Published by The Population Council, Pakistan Office.

11. Jackson C. Cognitive susceptibility to smoking and initiation of smoking during childhood: A longitudinal study. Prev Med 1998; 27:129-134.

12. Maqbool S. (2008) Tobacco use among women on the rise. The News International, p.20, July 28, 2008.
13. Tyas SL, Pederson LL. Psychosocial factors related to adolescent smoking: A critical review of the literature. Tob Control 1998; 7:409-20.

14. Ansari MA, Malik GQ, Mubasher M, Khan IA, Inam SNB.(1998)Community medicine and public health. 4 ed. Karachi: Time Traders, p.420

15. 14Robinson LA, Klesges RC, Zbikowski SM, Glaser R. Predictors of risk for different stages of adolescent smoking in a biracial sample. J Consult Clin Psychol 1997; 65: 653-62.

16. Zaman M, Irfan U, Irshad E. Prevalence of cigarette smoking among Peshawar University students. Pak J Chest Med 2002; 8: 9-18.

17. Wakefield MA, Chaloupka FJ, Kaufman NJ, Orleans CT, Barker DC, Ruel EE. Effect of restrictions on smoking at home, at school, and in public places on teenage smoking: Cross sectional study. BMJ 2000; 321: 333-37.

18. Tyas SL, Pederson LL. Psychosocial factors related to adolescent smoking: A critical review of the literature. Tob Control 1998; 7:409-20.

19. Jackson C. Cognitive susceptibility to smoking and initiation of smoking during childhood: A longitudinal study. Prev Med 1998; 27:129-134.

20. Pomrehn PR, Jones MP, Ferguson KJ, Becker SL. Tobacco use initiation in middle school children in three Iowa communities: Results of the Iowa Program Against Smoking (I-PAS). J Health Educ 1995; 26(Suppl: S92S100.

21. Hiscock R, Bauld L, Amos A, Fidler JA, Munafò M. Socioeconomic status and smoking: a review. Ann N Y Acad Sci. 2012 Feb;1248:107-23.

22. Haustein KO. Smoking and low socioeconomic status. Gesundheitswesen. 2005 AugSep;67(8-9):630-7

\section{CORRESPONDENCE ADDRESS}

Name: Dr. Rubeena Gul

Address: Department of Community Medicine, Khyber Medical College Peshawar.

Email: gul_rubeena@yahoo.com

Cell No: 0301-896-5970 